\title{
Firm growth and productivity in Belarus: New empirical evidence from the machine building industry*
}

\author{
Jesus Crespo Cuaresma ${ }^{\dagger} \quad$ Harald Oberhofer ${ }^{\ddagger}$ Gallina A. Vincelette ${ }^{\S}$
}

\begin{abstract}
Using a unique dataset comprising information for (up to) 153 firms in the machine building sector in Belarus, we investigate the determinants of firm growth for an economy where state ownership of enterprises is widespread. We use panel data models based on generalizations of Gibrat's law, total factor productivity estimates and matching methods to assess the differences in firm growth between private and state-contolled firms. Our results indicate that labor hoarding and soft budget constraints play a particularly important role in explaining differences in performance between these two groups of firms.
\end{abstract}

*The authors would like to thank two anonymous referees, Gérard Roland (editor in charge), Martina Bakanova, Benu Bidani, Sebastian Eckardt, Dima Kalechic, Martin Raiser, Pablo Saavedra, Karlis Smits, as well as participants in the Inclusive Growth and Competitiveness Course organized by the World Bank in Minsk in October 2011 for very helpful comments on earlier versions of the paper. The authors also gratefully acknowledge the funding for this research provided by the World Bank's Diagnostic Facility for Shared Growth as well as the opportunity to analyze firm level data in the machine building sector provided by the National Bank of the Republic of Belarus.

${ }^{\dagger}$ Department of Economics, Vienna University of Economics and Business (WU); World Population Program, International Institute of Applied Systems Analysis (IIASA); Wittgenstein Centre for Demography and Global Human Capital (WIC) and Austrian Institute for Economic Research (WIFO). Address: Augasse 2-6, 1090 Vienna (Austria). Email: jcrespo@wu.ac.at.

${ }^{\ddagger}$ Department of Economics and Social Science and Salzburg Centre of European Union Studies (SCEUS), University of Salzburg. Address: Residenzplatz 9, 5010 Salzburg (Austria). Email: Harald.Oberhofer@sbg.ac.at

$\S$ The World Bank. E-mail: gvincelette@worldbank.org 


\section{Introduction}

Belarus's economic growth experience is at odds with standard transition paradigms. Relatively early recovery and uninterrupted growth record since 1996 were not the result of opening and structural transformation of the economy. In comparison to other countries in Eastern Europe, which privatized their companies, shed labor and closed unprofitable enterprises, most Belarusian businesses remained state-owned. Belarus's impressive growth was not an outcome of the slow pace of economic reforms, however, but of its dependence on Russia's energy inputs. With comparative advantages in its main export markets (CIS, especially Russia), Belarus enjoyed a 15-year growth run, primarily led by energy-intensive export-oriented state industries. However, these advantages were transitory. Missed opportunities to pursue a structural transformation of the economy in the boom years narrowed the Belarus's possibilities to find new sources of growth and decrease the dependence of its industry on foreign resources. The future development of the state enterprise sector in Belarus is thus crucial for the overall success of the Belarusian economy. In this sense, a clear understanding of the functioning of state-owned firms is pivotal for the implementation of accurate economic policy measures.

In this paper we provide an in-depth analysis of firm growth and its drivers for the machine building industry in Belarus, which constitutes one of the key industries in the economy. Such an analysis is unique in several respects. On the one hand, due to the lack of available data, the Belarusian economy has been notoriously under-researched and this study presents the first thorough analysis of firm productivity in the country. On the other hand, given the particular degree of government control exercised in the Belarusian productive sector, our contribution provides relevant empirical results on the effects of state control in an environment which is unparalleled in the rest of Europe.

The main aim of the analysis is to address empirically the main forces driving firm profitability in Belarus. Assessing such a research question implies that we need to move beyond descriptive statistics to obtain more clear-cut insights on the determinant forces of firm growth in Belarus. We do so by using the workhorse model of the empirical firm growth literature, which builds upon Gibrat's law of proportionate growth. Based on a model of firm size convergence, we concentrate on assessing the heterogeneity in terms of productivity between state-controlled and private enterprises.

Our results indicate a significant degree of inefficient resource allocation in state-run firms. The investigation of the reasons behind the inefficiency in the allocation of production inputs requires to relate firm characteristics to their performance in terms of total factor productivity (TFP). We obtain total factor productivity (TFP) estimates applying standard modern econometric techniques and compare the resulting TFP measures across different types of firms. Simple mean comparison tests unambiguously reveal that state-controlled enterprises produce less efficiently (and also exhibit lower growth rates of TFP). In a final step, we unveil the sources of these observed productivity differences. We estimate TFP convergence models and apply matching estimators in order to assess whether labor hoarding and/or inefficient over-investment in physical capital are able to explain low levels and growth rates in TFP in state-controlled companies. Our results indicate that the inefficiencies in state-controlled enterprises are at least partly related to the use of input factors which makes them less competitive than their private counterparts.

The paper is organized as follows. We discuss the main data issues and present our definition of state ownership and state control in section two. Section three gives a descriptive view of 
firm growth dynamics in the Belarusian machine building industry. Section four estimates panel data models in the framework of Gibrat's law specifications. The estimates of such models allow us to assess differences in the firm growth process between state-owned enterprises and private firms. Section five focuses on the estimation of TFP at the firm level for the machine building industry. The sources of differences in TFP dynamics between state-controlled and non-statecontrolled firms are studied in section six. Section seven analyses resource misallocation in more detail using matching techniques. Section eight concludes.

\section{The machine building industry in Belarus: Data sources and definitions}

This paper utilizes a new balanced panel dataset for manufacturing firms active in the machine building industry in Belarus which spans the years 2005 to 2010. Machine building has been historically one of the specialization sectors of the Belarusian economy and is quantitatively one of the most relevant industrial sectors in terms of employment and production, accounting for approximately 22\% of total industrial output in 2010 (see World Bank 2012). Prestigious and well-known firms such as the Minsk Automobile Plant (MAZ) and the Minsk Tractor Works $(M T W)$ operate in the machine building industry $\left.\right|^{1}$

The data are based on a survey that is conducted by Belstat, the national statistical office of Belarus, and captures all firms operating in at least one of the 18 subsectors of the machine building industry $\left.\right|^{2}$ The available sample of firms only contains firms that report data in each and every year between 2005 and 2010. It includes the largest machine building firms and, in particular, a large share of state-controlled enterprises. Due to missing information for some important firm characteristics, the final dataset contains comprehensive balance sheet and income statement information for up to 153 firms resulting in a maximum of 914 firm-year observations 3

The official statistical office classifies a firm as state-owned if the state holds all shares (i.e., $100 \%$ ) of the respective firm. Obviously, this definition of state ownership would underestimate the true extent of state ownership in the machine building industry. For this reason, we apply a different definition for state influence in the machine building industry. According to World Bank (2012), the Belarusian Ministry of Industry is the main governmental agency that regulates the business activities of state-owned industrial companies. World Bank (2012) also discusses some of the main regulatory procedures that are carried out by the Ministry of Industry including the supervision of the use of energy and other materials or the definition of input norms for various production technologies in order to ensure an efficient use of resources in the production process. It is, thus, sensible to assume that the state could directly influence firms which report to the Ministry of Industry. Our measure of state ownership builds therefore on information whether a firm reports to the Ministry of Industry. This information

\footnotetext{
${ }^{1} \mathrm{~A}$ detailed description of the historical development of the machine building industry in Belarus is offered in World Bank (2012) (see Box 3.2).

${ }^{2}$ These subsectors are the automotive subsector, bearings, chemical and petroleum engineering, construction and road and municipal engineering, conveying machinery, electrical, industry interdisciplinary productions, industry metalwork, instrumentation, tools, machinery for light industry, food industry and household appliances, metallurgical engineering, mining and mining engineering, production of sanitary and gas equipment, radio industry, repair of machinery and equipment and tractor and agricultural machinery.

${ }^{3}$ See Section 3 for information on the variables and descriptive statistics.
} 
is gathered from the website of the Belarusian Ministry of Industry, which can be accessed at http://www.minprom.gov.by/organizacii

The largest state-controlled firms in the Belarusian machine building industry operate as de facto vertically integrated corporate groups. In most cases, a number of subcontracting stateowned firms produce intermediate goods which are then assembled by the large and prestigious producers, such as the above mentioned, $M A Z$ or $M T W$. Vertical integration, on the one hand, intends to strengthen governance structures within companies and ensures reliable supply of intermediate inputs (see, e.g., Williamson 1971, Helpman and Krugman 1985). On the other hand, vertical production chains might help hiding inefficiencies within the production chain. Thereby, internal transactions of goods and services at non-market prices may allow for crosssubsidization of inefficient sub-units within the vertical conglomerates. In order to investigate these issues explicitly using our data, we further distinguish in our analysis among main companies of the vertical chains, the affiliate firms and a third group of independent (not vertically integrated) firms.

\section{Firm growth in Belarus: Descriptive evidence from the machine building industry}

In this section, we briefly present descriptive evidence on the firm growth performance in the machine building industry and distinguish by the different types of ownership discussed above. The employment growth rate for the full sample of firms (see Table 1) indicates that the average firm in the machine building industry reduced its employment by approximately $2.5 \%$ yearly over the period considered. Interestingly, however, a small fraction of outlying firms exhibited impressive growth rates, with a maximum amount of more than $200 \%$ of employment growth. At a more disaggregated level, when comparing firms that are directly reporting to the Ministry of Industry with non-ministry-reporting firms, we find that the former group performed significantly worse. The average ministry-reporting firm exhibits an annual growth rate of $-4.1 \%$ while non-reporting firms, on average, keep their level of employment unchanged. Focusing on different types of firms, such as head companies of vertical chains, affiliates of such chains and independent firms, the descriptive statistics with regard to employment growth do not reveal remarkable differences across these groups. However, these types of firms may differ in other respects that affect their growth pattern. In our econometric analysis we will use this classification in order to analyse the impact of vertical integration on the growth performance of firms in the Belarusian machine building industry.

Disaggregating firm growth by sub-industry within the machine building sector reveals that the (average) firm size in terms of employment is relatively heterogeneous. The average firm size ranges from approximately 250 employees in the repair of machinery sector to approximately 1,100 employees in automobile production. During the observed time period, the median firm growth rates across all sub-industries imply that the respective firms reduce their number of

\footnotetext{
${ }^{4}$ We have also applied a different definition of state-ownership which is based on the national accounts definition. Accordingly, a firm is classified as state-owned if the state directly holds more than $50 \%$ of its shares. Additionally, for this definition a firm is regarded as privately-owned if state-ownership is less than $50 \%$. Finally, we introduce a third type of ownership, referred to as mixed-ownership, for firms with foreign ownership in addition to state and private owners. For more details on this alternative definition for (direct) state-ownership and private ownership and for the corresponding estimation results, which broadly confirm our findings, see Crespo Cuaresma, Oberhofer and Vincelette (2012).
} 


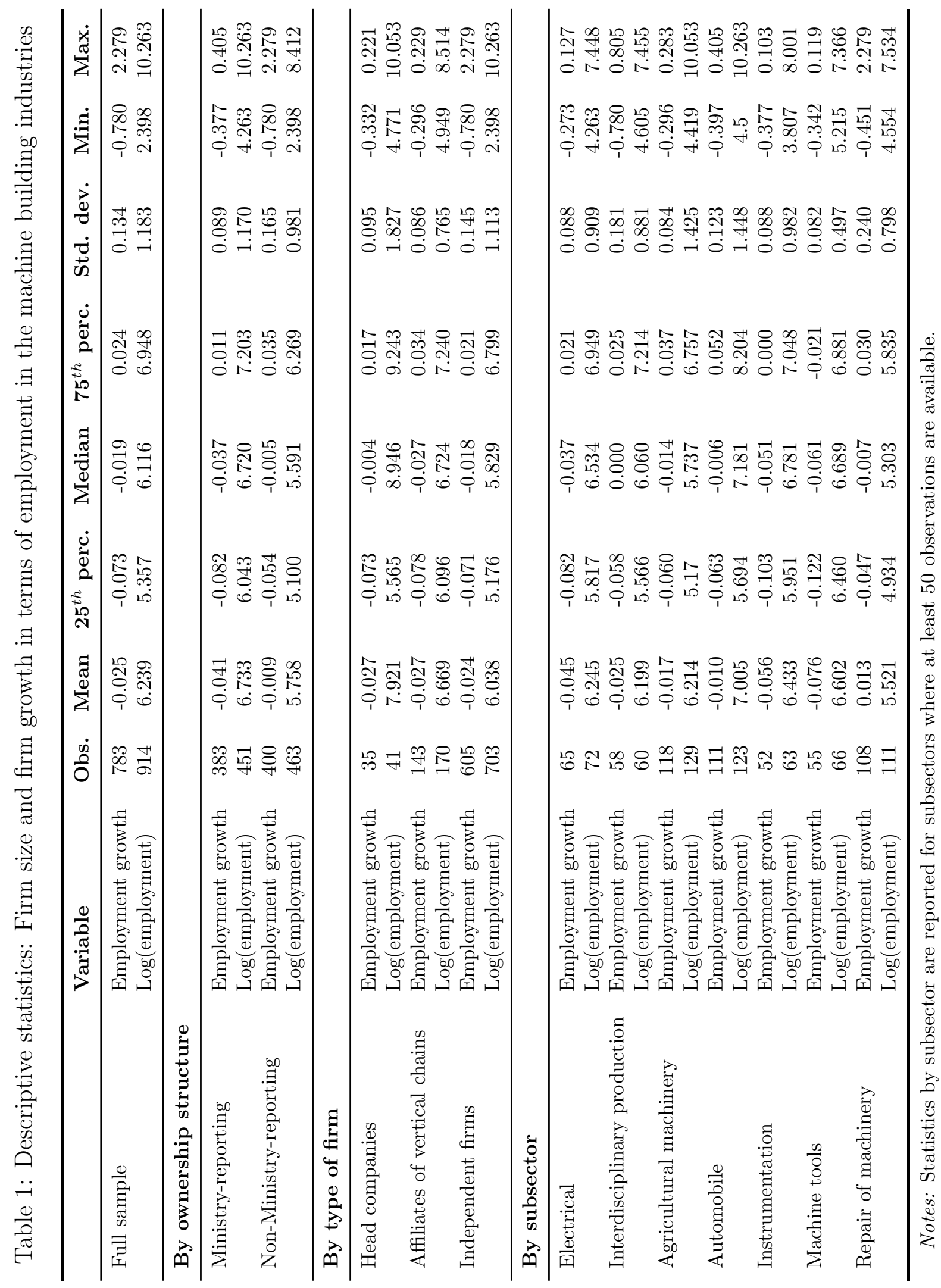




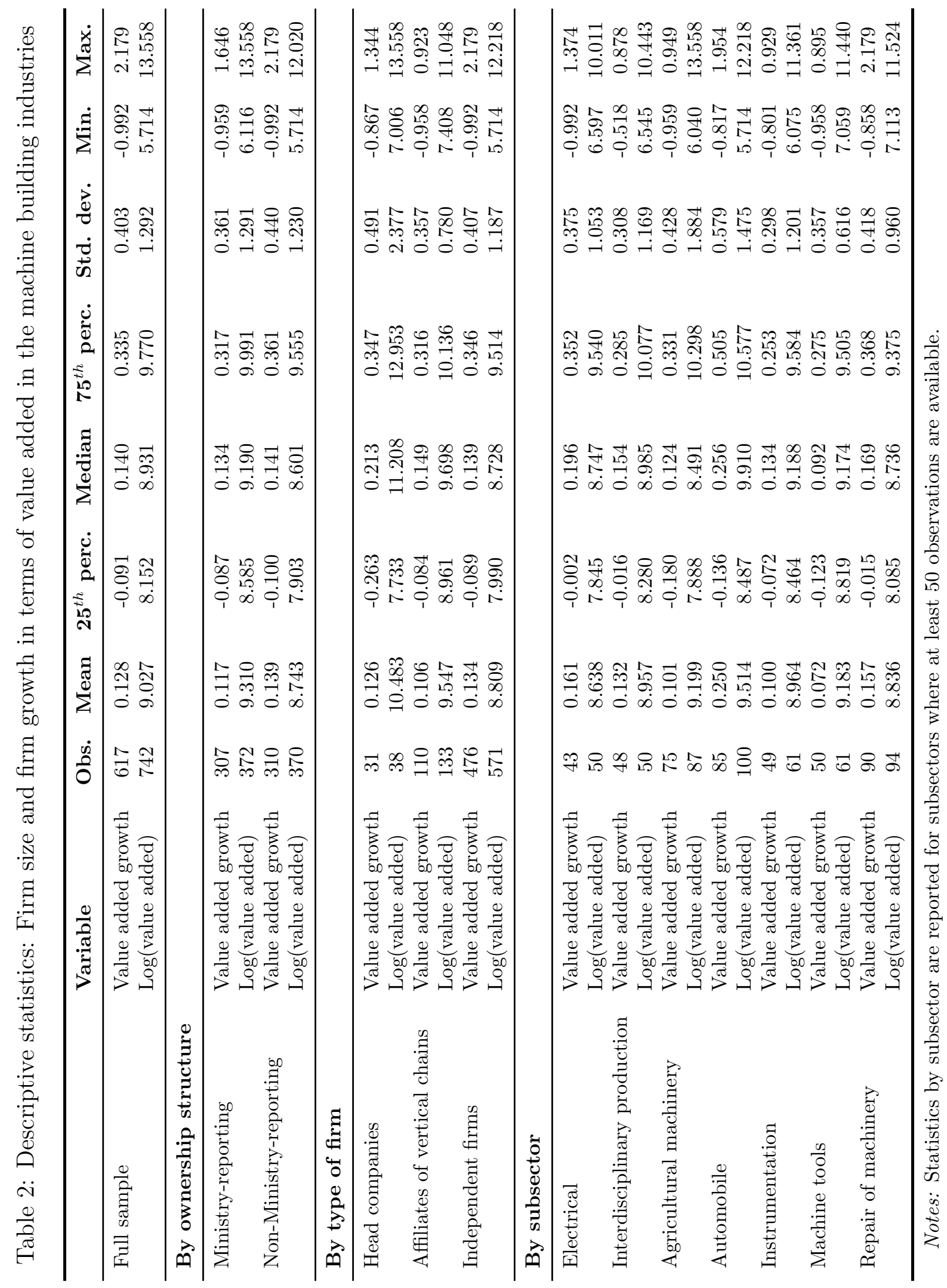


employees throughout. Here, the only exception is the interdisciplinary production industry, where the median firm does not change its number of employees from 2005 to 2010. These downsizing tendencies are most pronounced in the machine-tools sector, with a median firm growth rate of $-6.1 \%$.

Table 2 reports the same information for value added as a measure of firm size and firm growth.$^{5}$ Table 2 shows that the average value added growth rate is positive and well above $10 \%$ in most cases. However, one should stress that these results might be affected by asymmetric changes in overall prices (see Footnote 5 for more details). However, qualitatively they are similar to those obtained for employment. Non-ministry reporting firms again outperform those firms which report to the Ministry of Industry. This difference in the average value added growth performance is, however, considerably smaller than for employment. Focusing on different types of firms, affiliates of vertical production chains tend to exhibit the lowest value added growth rates on average. Additionally, independent firms also tend to outperform the head companies of the vertical production chains on average (although the opposite is the case if we consider the median growth rate of employment, thus indicating that the distribution of firm growth rates among heads of vertical chains is negatively skewed).

Finally, the disaggregation of value added growth rates by subsector reveals that value added growth is lowest in more traditional industries such as for production of agricultural machineries and for production of machine tools. To the contrary, the automobile industry shows impressive increases in value added, leading to an annual average growth rate of $25 \%$.

\section{Modeling firm growth dynamics in the machine build- ing industry}

\subsection{Gibrat's law: Firm size dynamics and convergence trends}

In his seminal contribution, Gibrat (1931) argues that firm growth is independent of firm size and, consequently, firm size follows a random walk. In the empirical firm growth literature this hypothesis is referred to as Gibrat's law of proportionate growth. Formally, this implies that the data generating process for firm growth can be specified as:

$$
\ln S_{i t}-\ln S_{i t-1}=\mu_{i t}
$$

where $S_{i t}$ denotes the size of firm $i$ at time $t$ (proxied by employment, value added or any other reasonable measure) and $\mu_{i t}$ is an iid random variable assumed to be normally distributed with $E\left[\mu_{i t}\right]=0$ and $\operatorname{var}\left[\mu_{i t}\right]=\sigma^{2}>0$ (see, e.g., Geroski 2005). Accordingly, the growth rate of firm size between time $t-1$ and time $t$ is given by $g_{i t}=\ln S_{i t}-\ln S_{i t-1}$.

In line with Chesher (1979), we assume that the error term is serially correlated and thus define $\mu_{i t}=\rho \mu_{i t-1}+\varepsilon_{i t}$, where $\varepsilon_{i t}$ is assumed to be white noise. Additionally, following Goddard, McKillop and Wilson (2002), Goddard, Wilson and Blandon (2002) and Giotopoulos and

\footnotetext{
${ }^{5}$ The value added figures are based on nominal values and thus might be affected by annual changes in the overall price level. This might especially be the case if changes in prices for final goods deviate from price changes for intermediate inputs and raw materials. In our regression analysis, we account for overall price changes by including year fixed effects in each specification.
} 
Fotopoulos (2010), among others, we reformulate a typical Gibrat's law type of equation in its dynamic representation. We also impose a potentially autocorrelated error term structure, additionally include (time-varying) control variables (denoted by $\mathbf{x}_{i t}$ with their respective parameters $\gamma$ ), account for individual fixed effects (captured by $\alpha_{i}$ ) and for (common) time-effects (denoted by $\delta_{t}$ ). This, in turn, leads to the following formulation of a generalized empirical firm growth equation,

$$
\begin{aligned}
g_{i t} & =\rho g_{i t-1}+(\beta-1) \ln S_{i t-1}+\gamma \mathbf{x}_{i t}+\alpha_{i}(1-\rho)+\delta_{t}+\mu_{i t}, \quad \text { where } \\
\mu_{i t} & =\varepsilon_{i t}+\rho(1-\beta) \ln S_{i t-2} .
\end{aligned}
$$

The estimation of (2) allows to jointly test whether firm growth is independent of firm size (i.e., $\beta=1$ ) and for autocorrelation in firm growth rates (i.e., $\rho \neq 0$ ). Gibrat's law holds if $\beta=1$ and $\rho=0$ simultaneously (see, e.g., Giotopoulos and Fotopoulos 2010). In this case, $\mu_{i t}$ reduces to $\epsilon_{i t}$.

From an econometric point of view, equation (2) is a dynamic panel data model, where typically a large number of cross-sectional units $i$ (firms) are observed over a relatively short time period. For this reason our empirical firm growth equation might most appropriately be estimated using approaches in the spirit of Arellano and Bond (1991) and Blundell and Bond (1998). These methods rely on Generalized Method of Moments (GMM) to estimate the model parameters. Indeed, building on previous papers, Oliveira and Fortunato (2006) and Giotopoulos and Fotopoulos (2010), among others, applied such estimators in order to investigate firm growth dynamics.

\subsection{Empirical specification}

To estimate the effect of the main drivers of firm growth in Belarus, we model firm growth from year $t-1$ to year $t$ as a function of firm growth in the previous period, firm size in period $t-1$ and a set of controls which we measure at period $t-1 \sqrt{6}$ The set of controls contains the log of total wage costs per employee, the log of a firm's exports, the log of previous years' investment and a firm's capacity utilization. Finally, we use fixed-effect estimators in order to control for time-invariant unobserved heterogeneity and year dummies which account for common shocks.7

With regard to the potential drivers of growth, per employee wage costs proxy the firms' production cost effectiveness. In this sense, firms with lower per employee wage expenses tend to be more competitive. With regard to a firm's growth performance, this implies that firms with lower wages per employees are expected to grow more rapidly. The specification also includes lagged exports as an explanatory variable to capture the impact of international competition on a firm's performance. Additionally, the inclusion of the level of investments allows to test more directly whether, on average, the surveyed Belarusian machine building firms tend to substitute factor inputs.

We examine also whether resources are allocated efficiently in the Belarusian machine building industry. For this reason, we incorporate a firm's lagged capacity utilization in our firm growth model. In line with standard neoclassical theories, we thus expect that those firms which appropriately utilize their inputs will have larger incentives to increase their demand for factor

\footnotetext{
${ }^{6}$ This modeling strategy intends to reduce the potential problem of reverse causality.

${ }^{7}$ Notice that the firm fixed effect also controls for differences across industries as long as the firms do not change the industry where the produce in.
} 
inputs. Consequently, we expect a positive impact of capacity utilization on a firm's employment growth performance.

We check for the robustness of our results by applying three different estimation strategies: least squares dummy variable (LSDV) estimator, difference GMM estimation based on Arellano and Bond (1991) and a bias-corrected least squares dummy variable estimator (CLSDV) based on Kiviet (1995) and Bruno (2005). The latter approach - which applies an approximation procedure to correct for the Nickell (1981) bias in LSDV estimation of dynamic fixed effects models - should be most appropriate for our application given the relatively small cross-sectional dimension of some of the sub-samples studied (see, e.g., Buddelmeyer, Jensen, Oguzoglu and Webster 2008).

\subsection{Estimation results}

Table 3 reports our baseline estimation results for employment growth using different subsamples for ministry-reporting, and non-ministry-reporting machine building firms. The three different estimation techniques lead to inconclusive results concerning the impact of lagged employment growth on the recent growth performance. The LSDV and the GMM estimators tend to show negative or positive but insignificant correlations in the firm growth rates over time. In contrast, the results obtained from the CLSDV estimator point to a significantly positive autocorrelation in firm growth over time, implying that employment growth dynamics tend to be reinforcing. Interestingly, the positive correlation in employment growth is mainly driven by ministry-reporting firms.

With regard to the impact of the initial firm size on firm growth, the different estimates commonly point to the fact that small firms tend to grow more rapidly than larger ones. The estimates of $(\beta-1)$ are all negative indicating that $\beta<1$. This result is well in line with the empirical firm growth literature which implies that, over time, firms tend to converge in their size 8

The qualitative impacts of the rest of the controls on firm growth are comparable across all three different types of fixed effects estimators. This points to the robustness of the results obtained. Moreover, utilizing the full sample of machine building firms and applying the preferred CLSDV estimator we are able to identify significant effects throughout. The parameter estimates of the lagged value of investments are positive throughout and significant in most of the cases implying that investments trigger employment growth in Belarusian machine building firms. This effect seem to be most pronounced for non-ministry reporting firms.

Finally, in line with our expectations, an increase in capacity utilization contributes to employment growth. Focusing again on the different sub-samples, it becomes obvious that this result is mainly driven by ministry-reporting firms. An increase in the level of exports, by contrast tends to reduce employment growth, although this effect is only significant when applying the LSDV and difference GMM estimators, respectively.

Table 4 provides additional estimation results for main companies of vertical chains its affiliates as well as for independent firms. Our estimation results again reject Gibrat's law, implying that smaller firms exhibit, ceteris paribus, higher employment growth rates. With regard to average wage costs, firms within the vertical production chains tend to have higher growth rates, while they are less cost-efficient. Interestingly, when focusing on the results obtained by the CLSDV

\footnotetext{
${ }^{8} \mathrm{~A}$ more detailed analysis of differences in fixed effect estimates may shed more light on this issue.
} 


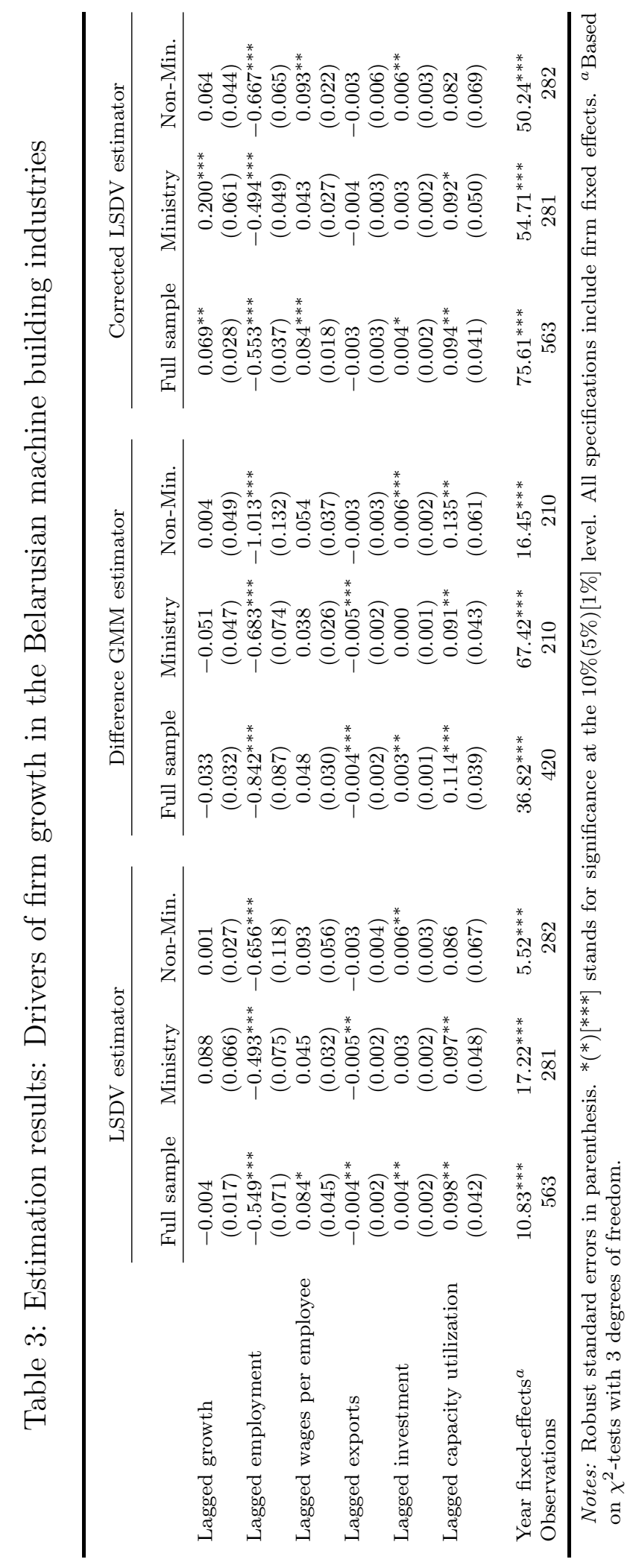




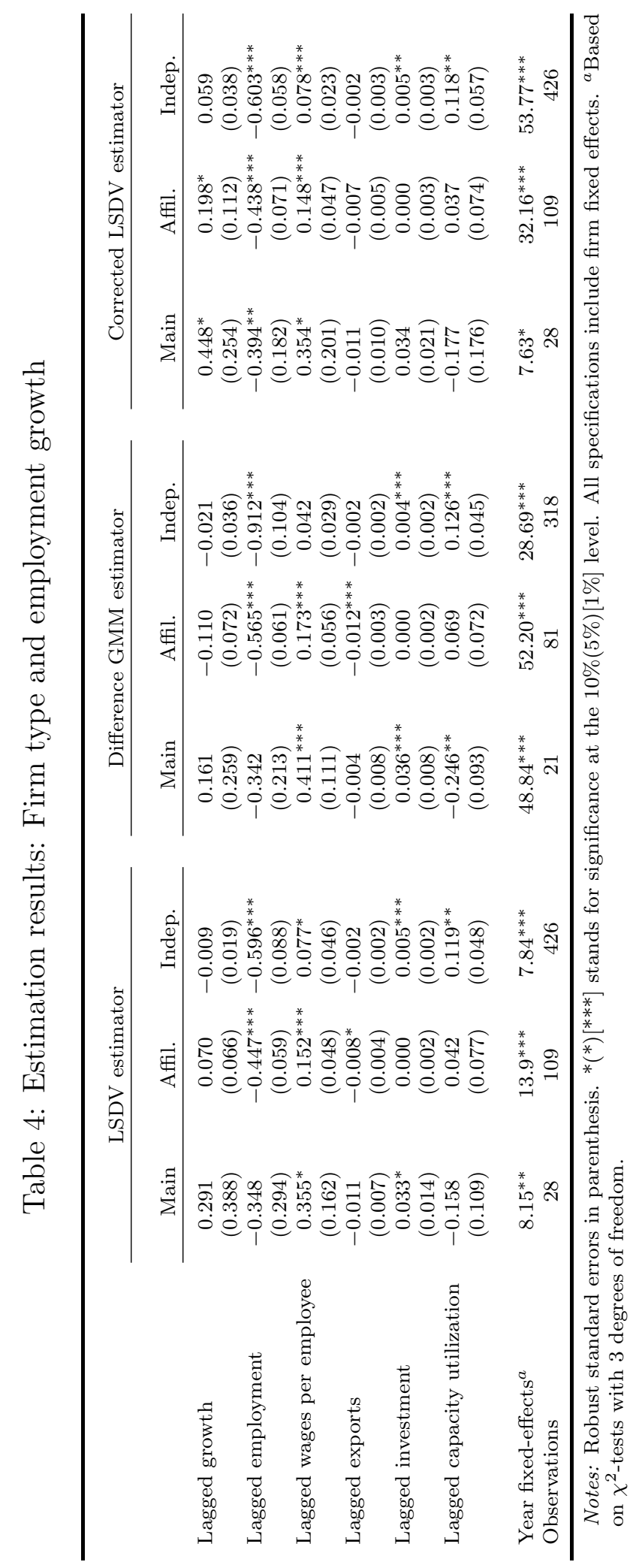


estimator provided in both Tables 3 and 4, this effect is insignificant only for the ministryreporting firms. Overall, this somehow surprising result might be explained by the unobserved differences in human capital of the employed labor force. Put differently, if firms employ more skilled workers, they tend to pay higher wages, but may also become more competitive. This in turn, might increase the demand for goods produced by the respective firms leading to higher employment growth rates. More detailed data on the educational attainment of employees, which are not available, would be necessary in order to assess this hypothesis empirically.

The negative internationalization effect of exports seems to be most important for affiliates of vertical conglomerates. This result supports the view that those firms which are rather inexperienced in being involved in international markets are more negatively affected by an increase in worldwide competition. Interestingly, the positive impact of investment activities on firm growth does not hold for affiliates of vertical production chains. Consequently, the employment growth performance of these firms is independent from an increase in capital inputs. In this regard, affiliates of vertical production chains are similar to ministry-reporting firms (again, see the corresponding results from Table 3). To the contrary, for all other types of firms (i.e., head of vertical chain and independent firms) an increase in capital leads to a subsequent increase in employment growth.

With regard to capacity utilization, we are only able to identify positive effects for independently organized firms, while in vertical production chains, we tend to find negative effects especially for the main firms. This result suggests that head companies with lower capacity utilization tend to experience higher increases in their number of employees. Evidently, this result once more supports the view that the approach taken for the organization of production in the Belarusian machine building industries leads to inefficient resource allocation. Thereby, the role of the relatively large vertical production chains seems to be especially questionable.

\section{Total factor productivity in the Belarusian machine building industry}

\subsection{Estimating total factor productivity}

To investigate productivity differentials between purely state-owned and non-state owned firms, we specify a functional form for the firm-specific production function. For the sake of simplicity, we apply a Cobb-Douglas production function, which is given by

$$
Y_{i t}=A_{i t} L_{i t}^{\alpha} K_{i t}^{\beta},
$$

where $Y_{i t}$ is a measure of output (e.g., value added) of firm $i$ at time $t$ and $L_{i t}$ and $K_{i t}$ denote labor and capital inputs, respectively. Finally, $A_{i t}$ captures firm-specific TFP, which simultaneously affects the marginal products of both inputs. Taking logarithms of the Cobb-Douglas production function yields

$$
\log Y_{i t}=\alpha \log L_{i t}+\beta \log K_{i t}+\log A_{i t},
$$

which forms the basis of our empirical specification.

Equation (4) implies that the residuals of the estimation of the (log) production function can be used as a measure of each firm's TFP. Theoretically, a firm (at least partly) knows its TFP 
and accordingly chooses its level of labor and capital inputs (e.g., more productive firms tend to produce larger quantities of a good and, consequently, utilize more capital and labor inputs). Formally, this implies that $\log A_{i t}$ comprises a systematic component and a true (random) error term, which modifies the (log) production function to

$$
\log Y_{i t}=\alpha \log L_{i t}+\beta \log K_{i t}+\omega_{i t}+\epsilon_{i t},
$$

where $\omega_{i t}$ represents a firm's TFP known only to itself and $\epsilon_{i t}$ is an iid error (see, e.g., Arnold 2005). Since $\omega_{i t}$ is correlated with the choice of labor and capital inputs, ordinary least squares (OLS) estimation of (5) inter alia suffers from the so-called simultaneity bias (or transmission bias), leading to inconsistent estimates of $\alpha, \beta$ and $\log A_{i t}$, respectively.

To successfully cope with the simultaneity problem when estimating TFP at the firm level the econometric literature offers various methodologies $?^{9}$ In case that the firm-specific systematic component in the error term is time-invariant (i.e. $\omega_{i t}=\omega_{i}$ ), standard fixed-effects estimation would allow to consistently estimate $\alpha$ and $\beta$ and thus, TFP would be accurately measured. However, in case of low within-firm variation the parameters of the production function would be only weakly identified and in case of $\omega_{i}$ varying over $t$ the fixed-effects estimates would also be inconsistent.

Olley and Pakes (1996) and Levinsohn and Petrin (2003) developed alternative (semi-parametric) estimation procedures, which explicitly deal with the simultaneity bias when estimating production functions. The former utilizes a firm's investment decision to proxy for differences in $\omega_{i t}$, while the latter one proposes the use of intermediate inputs in order to consistently estimate the production function. The Olley and Pakes (1996) estimation procedure can only be applied to firms with non-zero investments and therefore this approach typically excludes a large number of firms. In contrast, the Levinsohn and Petrin (2003) approach can be applied to all firms with a non-zero demand of intermediate inputs such as e.g., materials.

\subsection{Estimation results for total factor productivity}

In order to verify the robustness of our TFP results, we apply four different estimation strategies: (i) OLS, (ii) fixed-effects, (iii) the approach proposed by Olley and Pakes (1996) and (iv) the approached proposed by Levinsohn and Petrin (2003). Output is measured in terms of value added, defined as revenues minus costs for material inputs. Table 5 reports the corresponding estimation results for $\alpha$ and $\beta$.

With regard to the labor and capital elasticities the four different estimation strategies lead to conflicting results. For example, the input elasticities obtained from the simple OLS estimation indicate that the Belarusian machine building industry produces using a rather labor intensive technology, while the Levinsohn and Petrin (2003) procedure suggests the opposite.

Regarding the measurement of TFP, the residuals of the various production function estimates are of major interest. In contrast with the estimates of input elasticities, the TFP measures obtained form the four different procedures are very similar, with the correlation exceeding 0.95 in almost all cases. The only exception is the fixed effects estimator, which leads to a relatively poorly correlated TFP measure. However, in our application this latter estimator suffers from low within-firm variation leading to weakly identified input elasticities. For this reason, we

\footnotetext{
${ }^{9}$ For a recent survey on the estimation of TFP at the macroeconomic and the microeconomic level, see Del Gatto, Di Liberto and Petraglia (2011).
} 
Table 5: Estimation results: Cobb-Douglas production function in machine building industries

\begin{tabular}{lcccc}
\hline & \multicolumn{4}{c}{ Model } \\
\hline OLS & $\mathrm{FE}$ & $\mathrm{OP}^{a}$ & $\mathrm{LP}^{b}$ \\
\hline Labor & $0.583^{* * *}$ & $0.263^{* * *}$ & $0.417^{* * *}$ & $0.314^{* * *}$ \\
Capital & $(0.044)$ & $(0.064)$ & $(0.097)$ & $(0.088)$ \\
& $0.391^{* * *}$ & $0.158^{* *}$ & $0.414^{* * *}$ & $0.569^{* * *}$ \\
\hline Returns to scale & 0.974 & 0.421 & 0.834 & 0.883 \\
Wald test $^{c}$ & 2.10 & $53.09^{* * *}$ & 1.19 & 1.21 \\
\hline Observations & 914 & 914 & 759 & 914 \\
\hline
\end{tabular}

Notes: Standard errors in parenthesis. ${ }^{*}(*)[* * *]$ stands for significance at the $10 \%(5 \%)[1 \%]$ level. All regressions inlclude year fixed effects.

${ }^{a} \mathrm{OP}$ indicates the Olley and Pakes (1996) approach.

${ }^{b}$ LP indicates the Levinsohn and Petrin (2003) approach, where material costs proxy for unobserved productivity shocks. ${ }^{c}$ The Wald test assumes constant returns to scale (i.e., $\alpha+\beta=1$ ) as the null hypothesis.

use the TFP measures based on all four different estimation results in order to compare TFP between ministry-reporting and non-ministry-reporting Belarusian machine-building firms.

Our results indicate that TFP in non-ministry-reporting Belarusian machine-building firms exceeds the corresponding level of productivity in ministry-reporting enterprises (see Table 6) ${ }^{10}$ Excluding the unreliable fixed effects estimation results from our discussion, the upper part in Table6 indicates that, on average, non-ministry-reporting firms exhibit higher levels of TFP. Indeed, according to the results obtained from the other three estimation procedures (OLS, Olley and Pakes (1996) and Levinsohn and Petrin (2003)), the TFP levels of non-ministry-reporting firms substantially exceed the corresponding figures of their ministry-reporting counterparts. Some TFP estimators even indicate that the productivity levels for non-state-influenced firms are approximately doubled. The results presented in the bottom of Table 6 indicate that there are no significant differences with regard to TFP growth across the two types of firm. Taking into account all empirical results presented, the simple mean comparison tests unambiguously document that state-owned and state-influenced firms exhibit lower levels of TFP 11

\footnotetext{
${ }^{10}$ The Table provides the results of simple t-tests with unequal variances in the sub-populations for ministryreporting and non-ministry reporting firms.

${ }^{11}$ Moreover, the results in Crespo Cuaresma et al. (2012) document that this TFP gap has widened during the period from 2005 to 2010 when focusing on alternative measures of state ownership.
} 
Table 6: T-Test for Differences in TFP between ministry-reporting and nonministry-reporting firms

\begin{tabular}{lrcr}
\hline & $\begin{array}{c}\text { Ministry- } \\
\text { reporting }^{a}\end{array}$ & $\begin{array}{c}\text { Non-Ministry- } \\
\text { reporting }\end{array}$ \\
\multicolumn{4}{c}{ Levels in TFP } \\
\hline OLS & 0.988 & 1.494 & $-0.506^{* * *}$ \\
FE & 2.065 & 1.389 & $0.676^{* * *}$ \\
OP & 16.937 & 21.641 & $-4.704^{* * *}$ \\
LP & 4.513 & 6.189 & $-1.676^{* * *}$ \\
\hline \multicolumn{4}{c}{ Growth in TFP } \\
\hline OLS & 0.124 & 0.104 & 0.020 \\
FE & 0.119 & 0.104 & 0.015 \\
OP & 0.193 & 0.164 & 0.029 \\
LP & 0.150 & 0.122 & 0.028 \\
\hline
\end{tabular}

Notes: $* * *$ stands for significance at the $1 \%$ level.

${ }^{a}$ The group of firms directly reporting to the Ministry of Industry and the group of nonreporting firms comprise 439 and 442 firmyear observations, respectively.

\section{$6 \quad$ Unveiling the source of productivity differences}

The results in the previous section indicate that large productivity differences exist between state-owned enterprises and private firms in the Belarusian machine building industry. In this section, we investigate this issue further using models that aim at identifying the determinants of TFP differences across firms. We start by estimating convergence equations for TFP to assess whether the dynamics of productivity lead to corrections in the observed differences in TFP. In particular, we estimate a model given by

$$
\Delta \log A_{i t}=\rho_{0}+\rho_{1} S O E_{i t}+\lambda \log A_{i t-1}+\varepsilon_{i t},
$$

where a negative estimate of $\lambda$ indicates convergence. The presence of convergence dynamics would point to the fact that, on average, firms with low productivity levels tend to increase their productivity more than their high-productivity counterparts. We include a dummy variable for state-owned enterprises $(S O E)$ in the specification, whose parameter estimate informs us about whether state-controlled firms converge in the long-run to higher, lower or similar productivity levels as compared to non-ministry-reporting firms. 12

Since we are interested in unveiling convergence dynamics between firms, we do not include firm-specific fixed effects in the specification at this point 13 The results of the estimation of equation (6) are presented in Table 7 for the different TFP data obtained using the methods described above.

\footnotetext{
${ }^{12}$ The long-run equilibrium for private firms according to equation $(6)$ is given by $\rho_{0} /-\lambda$, while state-owned enterprises converge to $\left(\rho_{0}+\rho_{1}\right) /-\lambda$.

${ }^{13}$ All specifications include year fixed effects.
} 
Table 7: Convergence equations: TFP

\begin{tabular}{lcccc}
\hline & OLS & FE & OP & LP \\
\hline Lagged TFP & $-0.145^{* * *}$ & $-0.015^{* * *}$ & $-0.008^{* * *}$ & $-0.034^{* * *}$ \\
& $(0.024)$ & $(0.004)$ & $(0.001)$ & $(0.006)$ \\
State-owned & $-0.082^{* *}$ & -0.012 & $-0.046^{* *}$ & $-0.060^{*}$ \\
& $(0.036)$ & $(0.030)$ & $(0.033)$ & $(0.033)$ \\
Intercept & $0.256^{* * *}$ & $0.071^{*}$ & $0.344^{* * *}$ & $0.317^{* * *}$ \\
& $(0.056)$ & $(0.037)$ & $(0.055)$ & $(0.055)$ \\
\hline $\mathrm{R}^{2}$ & 0.067 & 0.012 & 0.094 & 0.085 \\
Obs. & 724 & 724 & 724 & 724 \\
\hline
\end{tabular}

Notes: Each column refers to a different TFP estimate, abbreviations as in preceding section. Robust standard errors in parenthesis. $*(*)[* * *]$ stands for significance at the $10 \%(5 \%)[1 \%]$ level.

The qualitative conclusions from the estimation results appear independent from the TFP data used. In all cases, the results indicate convergence dynamics in total factor productivity, as can be inferred from the negative and significant parameter estimates attached to the lagged TFP level. However, the long-run equilibrium towards which productivity levels converge is significantly lower for state-controlled enterprises as compared to non-ministry-reporting firms. This result is reflected in the negative (and in two cases significant) coefficient estimates attached to the dummy variable which identifies state-owned firms.

Once differences in TFP dynamics have been found, the question remains concerning where such differences come from. Labor hoarding, overinvestment or unproductive investments are potential explanations for such a result. In our next modeling step, we expand equation (6) adding new explanatory variables with the aim of explaining the source of productivity differences across firm groups. The general specification which we estimate is given by

$$
\Delta \log A_{i t}=\rho_{0}+\rho_{1} S O E_{i t}+\lambda \log A_{i t-1}+\lambda_{1} S O E_{i t} \log A_{i t-1}+\gamma_{1} \Delta \log L_{t}+\gamma_{2} \Delta \log K_{t}+\varepsilon_{i t} .
$$

In such a model, we allow for a different speed of convergence for state-controlled and nonministry-reporting firms, which is captured by the interaction between the SOE dummy and $\log A_{i t-1}$, and include employment growth and the growth rate of capital as additional determinants of TFP growth. The explanatory power of employment growth and/or physical capital growth for TFP dynamics should indicate which input dynamics can explain different productivity developments across enterprises in the machine-building industry. If state-controlled firms performed poorly in terms of productivity growth because of labor hoarding, differences in employment growth should be able to account at least partly for TFP growth differences. Conversely, if unproductive investments were responsible for these differences, the growth in capital stock should be a significant determinant of TFP growth gaps between firms.

Table 8 presents the results of the estimation of (7) using standard OLS methods (where between-firm differences are the dominating source of variation) and fixed effects estimation (which aims at explaining within-firm changes in productivity). Starting with the OLS results, the most remarkable result in Table 8 is that, once that model $(6)$ is expanded to the specification given by (7), the $S O E$ dummy loses its significance for all TFP estimates. 


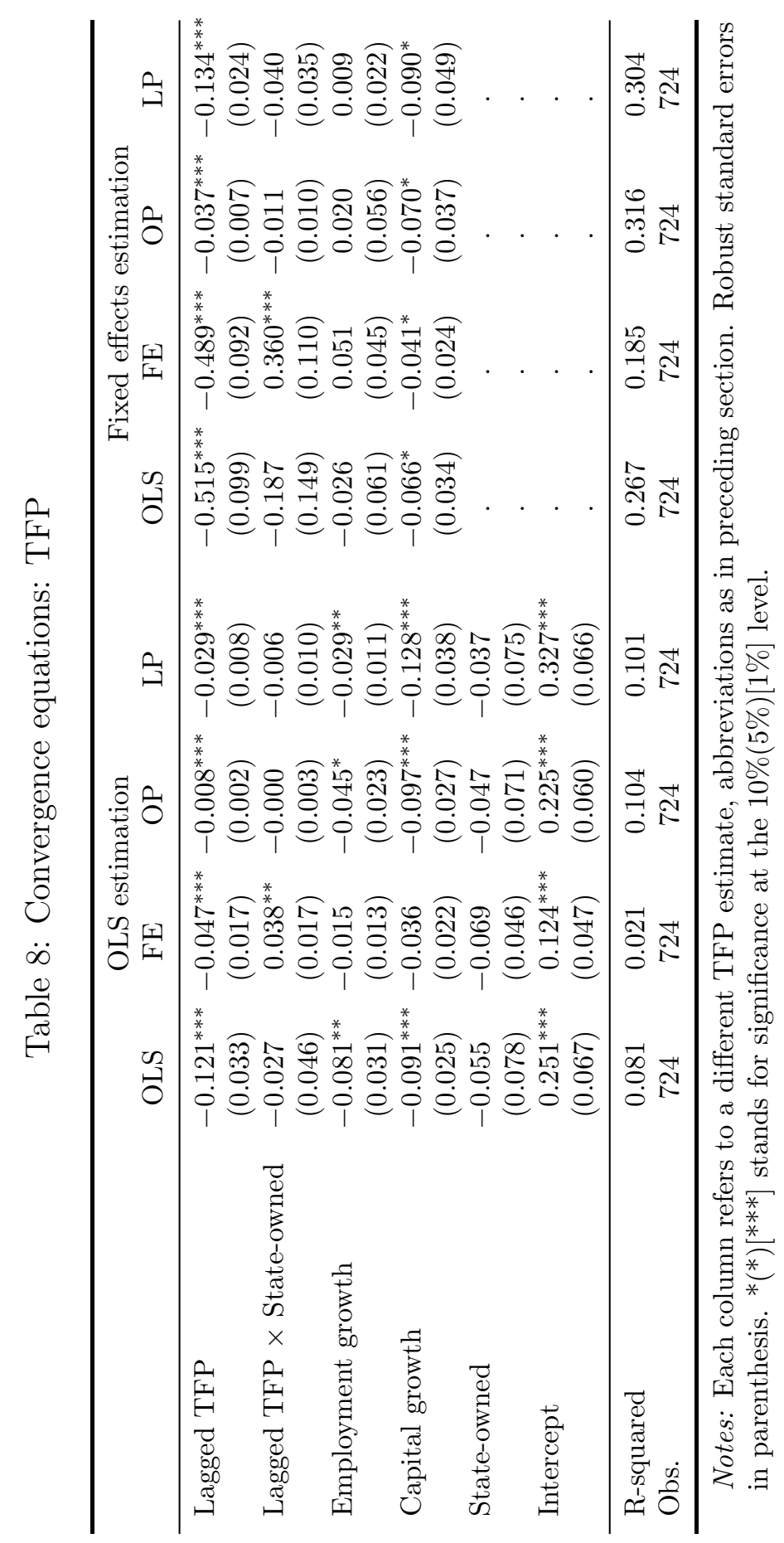


This result, together with the estimates of the covariates included in the specification, implies that the differences in TFP growth between state-controlled and non-state-controlled firms can be explained by (a) their different dynamics in terms of adjustment to the equilibrium (mirrored in the significant parameters for the interaction of $S O E$ and $\log A_{i t-1}$ for fixed-effects based TFP measures) and (b) differences in the accumulation of production factors. The second explanation seems to be more strongly supported by the data. Three of the specifications indicate that the lower TFP growth emanates from the fact that firms have increased employment in a framework where production was either decreasing or increasing at a lower rate than labor input. All 8 different specifications, applying either between or within firm variation, commonly indicate that the source of productivity growth differences is based on unproductive investment in physical capital. Put informally, inefficient capital allocation within ministry-reporting firms seems to be a robust driving force of the low level of productivity growth observed in these firms. Overall, the conclusion that can be inferred from the OLS and FE results in Table 8 is that growth of input factors, in general, might explain partially lower TFP growth rates in state-controlled enterprises.

Taking into account the developments in aggregate production during the period considered, which have been marked by the effects of the global recession, our results indicate that the likely reason for the polarization in firm productivity between state-owned enterprises and nonstate-controlled firms is related to a potential missallocation of resources at the firm level. The loss of productivity in state-controlled enterprises can, at least partly, be explained by suboptimal decisions when it comes to labor allocation and capital investments during the period 2005-2010.

\section{Soft budget constraints and inefficient resource allo- cation}

The results from the previous section indicate the existence of inefficiencies in state-owned firms due to labor hoarding and/or unproductive investments. This section provides results using an alternative method to investigate this issue further. We focus explicitly on potentially prevailing soft budget constraints (SBCs) in the sample of firms. SBCs in state-owned enterprises might arise if the government favours these companies vis-à-vis private competitors. Such SBCs may take the form of access to below cost energy inputs, preferential tax treatment, preferential access to financing, subsidy of interest rate payments or preferential access to procurement tenders 14

In order to empirically analyze whether SBCs are observable in the Belarusian machine building industry, we apply a simple matching approach. State ownership cannot be credibly considered to be comparable with a treatment which is applied randomly across firms. Some (eventually unobservable) firm characteristics tend to affect both the probability of being state-owned and their economic performance, so sample selection is a potential statistical problem in our empirical application. For our study, we draw on existing theoretical contributions related to matching estimators for average treatment effects by Abadie and Imbens (2006) and implement the corresponding estimators as discussed in Abadie, Drukker, Herr and Imbens (2004) ${ }^{15}$

\footnotetext{
${ }^{14}$ Kornai et al. (2003) provide an excellent survey on SBCs. See also World Bank (2012).

${ }^{15}$ Literature reviews on matching estimators are provided by Cobb-Clark and Crossley (2003), Imbens (2004), Blundell and Costa Dias (2009) and Imbens and Wooldridge (2009).
} 
Matching estimators are well established in the so-called program evaluation literature, which intends to identify the economic impact of certain policy measures. In our case, the policy variable (treatment) of interest is state-ownership which is again measured with the information on firms reporting to the Ministry of Industry, and our aim is to assess whether labor hoarding and/or unproductive investments are present in these firms.

The two most commonly used estimators for treatment effects of policy intervention are the average treatment effect (ATE) and the average treatment effect on the treated (ATT). The former estimates the average effect of the policy program for a randomly drawn firm from the whole sample while the latter only considers the sub-sample of ministry-reporting firms. Formally, these two estimators are given by (see, e.g., Wooldridge 2010)

$$
\begin{aligned}
\tau_{\mathrm{ATE}} & =E\left(y_{1}-y_{0}\right), \text { and } \\
\tau_{\mathrm{ATT}} & =E\left(y_{1}-y_{0} \mid w=1\right),
\end{aligned}
$$

where $w=1$ if a firm reports to the Ministry of Industry and 0 otherwise. $y_{1}$ and $y_{0}$ denote the outcome under treatment and non-treatment, respectively. The problem in this setting is that for each firm only one outcome is observable. If a firm is state-owned, we only observe $y_{1}$; while for non-ministry-reporting firms only $y_{0}$ is available. The matching approach (among other methods) intends to identify the counterfactual unobservable outcome for each firm. Here, the basic idea is that the most similar firms with regard to the outcome-relevant characteristics in the control group constitute the best estimate for the unobservable counterfactual outcome. If for example two firms, one state-owned and the other non-ministry-reporting, are equal in all determinants of the final outcome an observable difference between these two can be traced back to the influence of the Ministry of Industry.

In our empirical application, we are interested in phenomena such as labor hoarding and inefficient investment in physical capital. We evaluate the existence of SBCs taking explicitly the vertical organizational structure of firms into account. We start with an analysis focused on subsidiary firms of these vertical chains as well as on independent firms ${ }^{16}$ We restrict our matching procedure to only consider firms which are of the same type as the respective firms, and thus, we compare our outcomes of interest only for subsidiary firms or independent firms.

Table 9 provides the results. The upper part of Table 9 presents the results when we average our log-differences for the ATE and ATT over both types of firms while the second and third parts individually focus on the sub-samples of subsidiary and independent firms, respectively. For all three different matching estimators the counterfactual outcome for each firm is based on the three nearest neighboring firms based on the matching variables.

Our various matching estimators commonly restrict the comparison to the same type of firms in the same year. This guarantees that we only compare subsidiaries of vertical production chains and independent firms with each other, respectively. Moreover, due to the cyclical behavior of the whole economy during our observation period, we only compare labor and capital inputs within the same years. Additionally, for our analysis of employment and physical capital, we match firms based on their level of TFP, TFP growth, profits, value added, revenues and the firm's industrial sub-sector as well as its regional location. Here, TFP is calculated as the average of our four different measures.

\footnotetext{
${ }^{16}$ Unfortunately, all head firms of the large networks report to the Ministry of Industry and, thus, our dataset lacks a proper control group for this subset of firms.
} 
Table 9: Matching Estimates for SBCs

\begin{tabular}{|c|c|c|}
\hline & oyment $^{a}$ & Physical capital $^{a}$ \\
\hline \multicolumn{3}{|c|}{$\begin{array}{l}\text { Subsidiaries and Independent Firms } \\
\text { (3 nearest neighbours) }\end{array}$} \\
\hline ATE & $\begin{array}{l}0.443^{* *} \\
(0.099)\end{array}$ & $\begin{array}{l}0.785^{* * *} \\
(0.128)\end{array}$ \\
\hline ATT & $\begin{array}{l}0.467^{* *} \\
(0.103)\end{array}$ & $\begin{array}{l}1.000^{* * *} \\
(0.108)\end{array}$ \\
\hline \multicolumn{3}{|c|}{$\begin{array}{l}\text { Subsidiaries Firms } \\
\text { (3 nearest neighbours) }\end{array}$} \\
\hline ATE & $\begin{array}{l}0.680^{* *} \\
(0.281)\end{array}$ & $\begin{array}{c}0.196 \\
(0.205)\end{array}$ \\
\hline ATT & $\begin{array}{l}0.732^{* *} \\
(0.282)\end{array}$ & $\begin{array}{c}0.256 \\
(0.206) \\
\end{array}$ \\
\hline \multicolumn{3}{|c|}{$\begin{array}{l}\text { Independent Firms } \\
\text { (3 nearest neighbours) }\end{array}$} \\
\hline ATE & $\begin{array}{l}0.832^{* * *} \\
(0.125)\end{array}$ & $\begin{array}{l}0.797^{* * *} \\
(0.152)\end{array}$ \\
\hline ATT & $\begin{array}{l}0.989^{* *} \\
(0.100)\end{array}$ & $\begin{array}{l}1.104^{* * *} \\
(0.125)\end{array}$ \\
\hline
\end{tabular}

Notes: Robust standard errors in parenthesis. $* *(* * *)$ stands for significance at the $5 \%(1 \%)$ level.

${ }^{a}$ Matching is based on level of TFP, TFP growth, profits, exports, value added, sub-industry and time fixed effects. 
With regard to these two input variables, our results are well in line with what we have obtained so far. In particular, as indicated by both the ATEs and the ATTs, state-controlled firms with most similar characteristics employ more workers as compared to non-reporting enterprises. For example, the average subsidiary or independent state-controlled firm employs $46.7 \%$ more workers than it would employ as non-controlled company. Similarly, the ATT including both types of firms indicates that for the same level and growth rate of TFP and all other matching variables, the capital input of state-owned enterprises is roughly twice as high as in non-ministry-reporting firms. This reinforces our argument that not only labor hoarding but also overinvestment is important in the Belarusian machine building industry.

\section{Concluding remarks}

This paper evaluates the economic performance of state-controlled versus non-state-owned firms in the Belarusian machine-building industry. Empirically, the focus is on the firm growth performance and on total factor productivity. We apply standard modern methods from the empirical firm growth literature and our results indicate that firm growth (in terms of employment) in state-controlled firms might be unsustainable and driven by inefficient resource allocation. Our results also indicate that vertical production chains might be particularly important for explaining the source of the misallocation of resources. We use matching techniques to investigate the instruments used to enable such resource misallocation. Soft budget constraints appear to be in place in the sector. The group of state-controlled subsidiaries of vertical networks tends to benefit most from such soft budget constraints.

From an economic point of view, these firm growth trends can have very relevant effects on firm productivity dynamics. Using estimates of total factor productivity (TFP), which account for the simultanity bias, we unambiguously reveal that state-owned firms are less efficient than their non-ministry-reporting counterparts. Moreover, TFP convergence equations show that the dynamics and long-run level of productivity is substantially lower for this group of firms. Labor hoarding and unproductive overinvestment are possible explanatory factors for these differences. With the aid of extended TFP convergence equations, we are able to demonstrate that for the Belarusian machine building industry the unsustainable increases in input factors might be responsible for the low level of productivity in state-controlled firms. These results are further confirmed using matching methods, where potential sample selection issues are accounted for.

In the long-run, the inefficiencies which have been identified are likely to lead to adverse economic consequences. In a globalized world economy, inefficient firms will not be competitive and, thus, Belarusian machine building firms will find it hard to successfully participate in international markets. Relying exclusively on local demand would not allow for these firms to produce at the minimum efficient scale. 


\section{References}

Abadie A., Drukker D., Herr J. L., and Imbens G. W. (2004), 'Implementing matching estimators for average treatment effects in Stata', Stata Journal 4, 290-311.

Abadie A. and Imbens G. W. (2006), 'Large sample properties of matching estimators for average treatment effects', Econometrica 74, 235-267.

Arnold J. M. (2005), 'Productivity estimation at the plant level: A practical guide'

Arellano M. and Bond S. (1991), 'Some tests of specification for panel data: Monte Carlo evidence and an application to employment equations', Review of Economic Studies 58, 277297.

Blundell R. and Bond S. (1998), 'Initial conditions and moment restrictions in dynamic panel data models', Journal of Econometrics 87, 115-143.

Blundell, R. and Costa Dias M. (2009), 'Alternative approaches to evaluation in empirical microeconomics', Journal of Human Resources 1, 565-640.

Bruno G.S. F. (2005), 'Approximating the bias of the LSDV estimator for dynamic unbalanced panel data models', Economics Letters 87, 361-366.

Buddelmeyer, H., Jensen P. H., Oguzoglu, U. and Webster, E. (2008), 'Fixed effects bias in panel data estimators', IZA Discussion Paper No 3487, Institute for the Study of Labor.

Chesher A. (1979), 'Testing the law of proportionate effect', Journal of Industrial Economics 27, 403-411.

Cobb-Clark, D. A. and Crossley T. (2003), 'Econometrics for evaluations: An introduction to recent developments', Economic Record 79, 491-511.

Crespo Cuaresma, J., Oberhofer H. and Vincelette, G. A. (2012), 'Firm growth and productivity in Belarus: New empirical evidence from the machine building industry', World Bank Policy Research Working Paper No. 6005, The World Bank.

Del Gatto M., Di Liberto A. and Petraglia C. (2011), 'Measuring productivity', Journal of Economic Surveys 25, 952-1008.

Geroski, P. A. (2005), 'Understanding the implications of empirical work on corporate growth rates', Managerial and Decision Economics 26, 129-138.

Gibrat, R. (1931), Les Inequalities Economiques, Sirey, Paris.

Giotopoulos I. and Fotopoulos G. (2010), 'Intra-industry growth dynamics in the Greek services sector: Firm-level estimates for ICT-producing, ICT-using, and non-ICT industries', Review of Industrial Organization 36, 59-74.

Goddard J. A., McKillop D. G. and Wilson J.O. S. (2002), 'The growth of US credit unions', Journal of Banking and Finance 26, 2327-2356.

Goddard J. A., Wilson J.O. S. and Blandon P. (2002), 'Panel tests of Gibrat's law for Japanese manufacturing', International Journal of Industrial Organization 20, 415-433. 
Helpman, E. and Krugman P. (1985), Market Structure and Foreign Trade, Cambridge, MIT Press.

Imbens, G. W. (2004), 'Nonparametric estimation of average treatment effects under exogeneity: A review', Review of Economics and Statistics 86, 4-29.

Imbens, G. W. and Wooldridge J. M. (2009), 'Recent developments in the econometrics of program evaluation', Journal of Economic Literature 47, 5-86.

Kiviet, J. (1995), 'On bias, inconsistency, and efficiency of various estimators in dynamic panel data models', Journal of Econometrics 68, 53-78.

Kornai, J., Maskin, E. and G. Roland (2003), Understanding the soft budget constraint, Journal of Economic Literature XLI, 1095-1113.

Levinsohn J. and Petrin A. (2003), 'Estimating production functions using inputs to control for unobservables', Review of Economic Studies 243, 317-342.

Nickell, S. J. (1995), 'Biases in dynamic models with fixed effects', Econometrica 49, 1417-1426.

Oliveira B. and Fortunato A. (2006), 'Firm growth and liquidity constraints: A dynamic analysis', Small Business Economics 27, 139-156.

Olley S. and Pakes A. (1996), 'The dynamics of productivity in the telecommunications equipment industry', Econometrica 64, 1263-1297.

Williamson, O. E. (1971), The vertical integration of production: Market failure considerations, American Economic Review Papers and Proceedings 61, 112-123.

Wooldridge, J. M. (2010), Econometric Analysis of Cross Section and Panel Data, Second Edition, MIT Press, Cambridge, MA and London.

World Bank. (2012), Economic Transformation for Growth: Country Economic Memorandum for the Republic of Belarus, Washington, D.C., The World Bank. 